\title{
THE EFFECTS OF MASTECTOMY ON BODY IMAGE AND CULTURAL IDENTITY IN JAPANESE WOMEN
}

\author{
HARADA MIHOKO, R.N, M.A, Ph.D, Kansai University of Nursing and Health Sciences
}

\section{Introduction}

The concept of body image is defined differently by each culture Therefore, in Japan, the cultural aspects of Japanese Confucian teaching and the idea that "I care about others' eyes" should be considered. The purpose of this study was to examine the influence of body image from a cultural viewpoint on Japanese women who had undergone mastectomy.

\section{Results}

Table1. I Group who underwent surgery since $2004 \mathrm{n}=7$

\begin{tabular}{|c|c|c|c|}
\hline Case & Age & Operation type & Year \\
\hline A & 60 & Breast conserving & 2012 \\
\hline F & 60 & Breast conserving & 2009 \\
\hline G & 50 & Reconstruction & 2009 \\
\hline H & 50 & Breast conserving & 2009 \\
\hline J & 70 & Reconstruction & 2013 \\
\hline L & 50 & Breast conserving & 2012 \\
\hline M & 60 & Modified & 2010 \\
\hline
\end{tabular}

\section{Methods}

Semistructured interviews were conducted with 14 Japanese women who had undergone mastectomy. These women were grouped on the basis of operation type and a qualitative inductive analysis was performed.

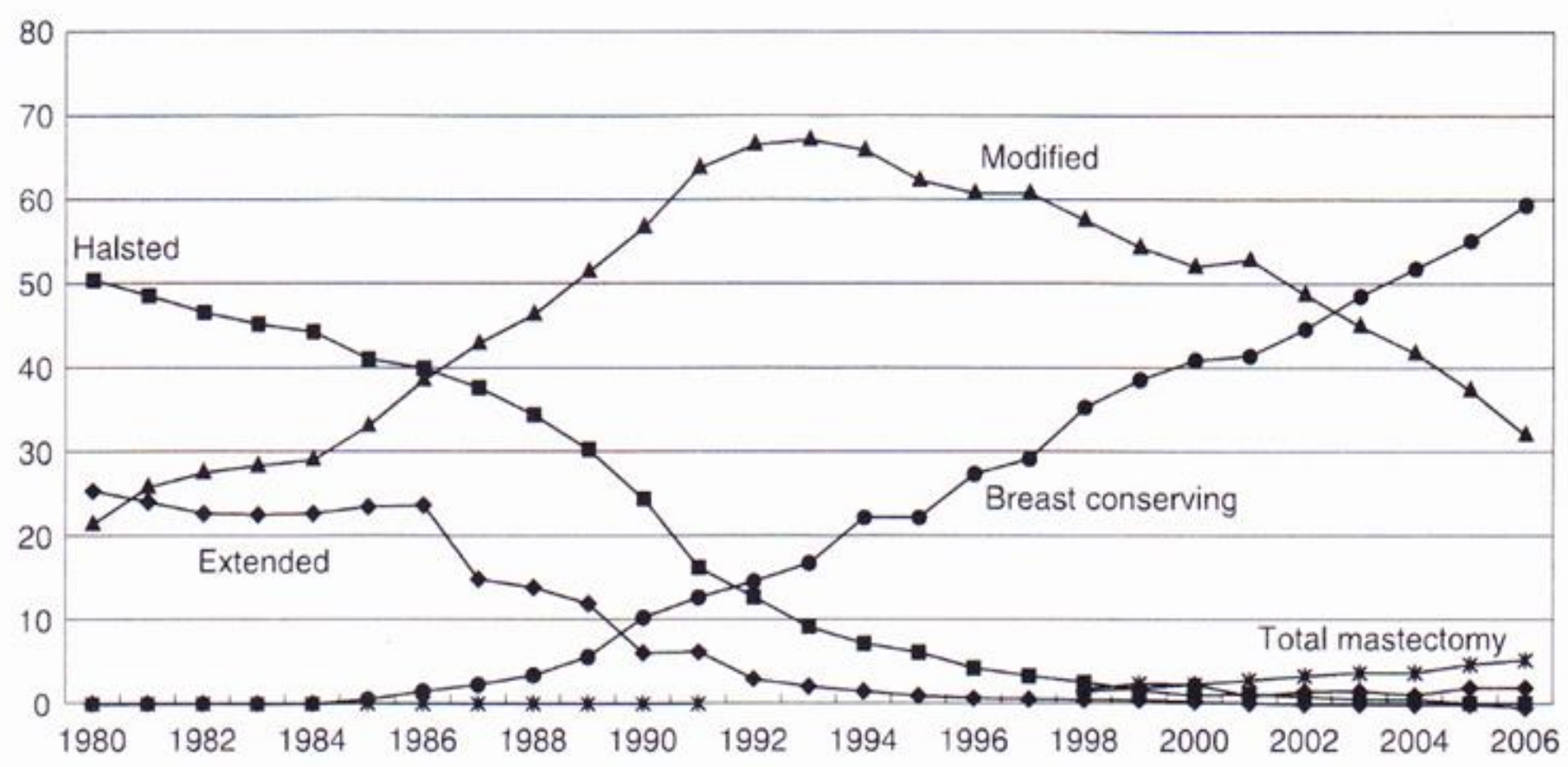

Figure1.Transition of surgery for breast cancer in Japan (Sonoo $\mathrm{H}$,et al.; Results of questionnaire survey on breast cancer surgery in Japan 2004-2006. Breast Cancer, 15:3-4,2008)
Table2. II Group (A group)who underwent surgery from 1987 on to less than 2004. $\mathrm{n}=4$

\begin{tabular}{|c|c|c|c|}
\hline Case & Age & Operation type & Year \\
\hline C & 50 & Modified & 1998 \\
\hline D & 60 & $\begin{array}{c}\text { Breast } \\
\text { conserving(both) }\end{array}$ & 2003 \\
\hline I & 60 & Breast conserving & 1992 \\
\hline K & 40 & Breast conserving & 2002 \\
\hline
\end{tabular}

Table3. II Group (B group)who underwent surgery before $1987 \quad n=3$

\begin{tabular}{|c|c|c|c|}
\hline Case & Age & Operation type & Year \\
\hline B & 60 & Modified & 1985 \\
\hline E & 70 & $\begin{array}{l}\text { R : Halsted } \\
\text { L : Modified }\end{array}$ & $\begin{array}{c}\text { R } 1983 \\
\text { L 2003 }\end{array}$ \\
\hline N & 80 & Halsted & 1975 \\
\hline
\end{tabular}

Table4. Age and number of subjects who had surgery

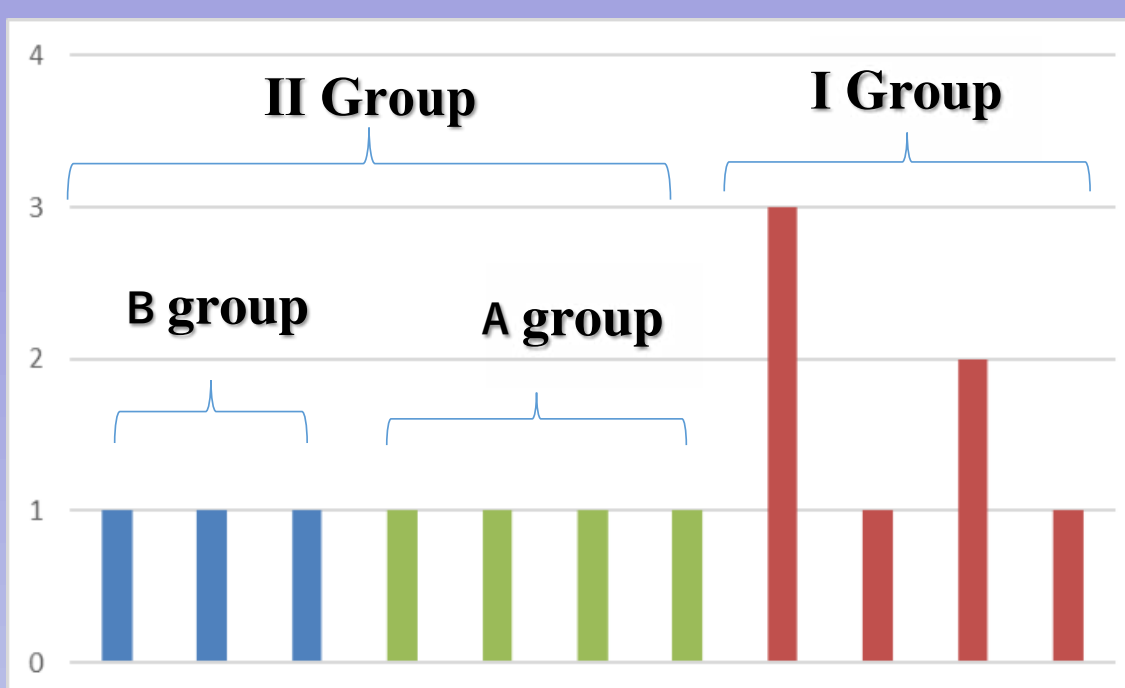

\section{Breast, live, feminine}

Positive body image

- Not even

- It was good to have surgery - No problem

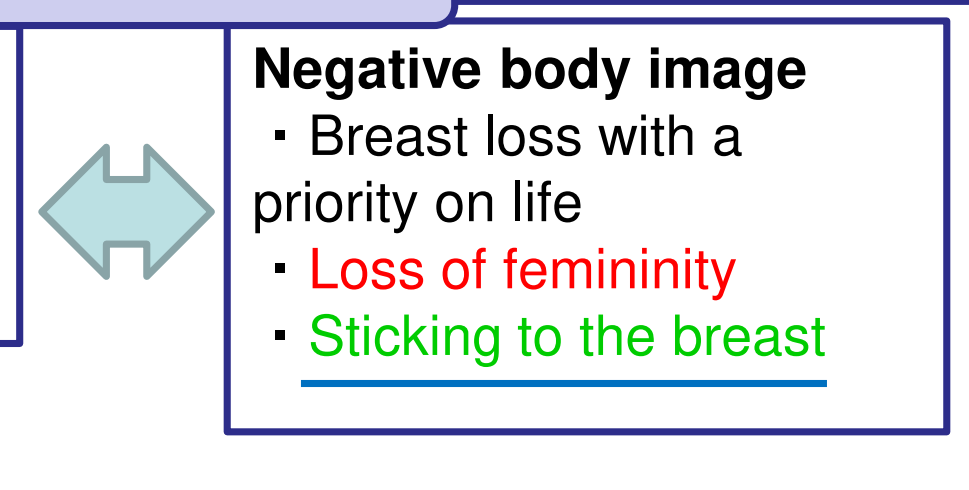

Transformation process of body image

\section{Conclusion}

Clearly, a characteristic body image in relation to the operation type was observed. Japanese people are influenced by Confucianism, and accepting cosmetic surgery and transplantation is difficult for them. However, an increasing number of people are in need of reconstruction. The desire to have an improved breast appearance suggests that Japanese women have changed their body image perception beyond culture, favoring a Western body image.

\section{Inpressions of surgical} wounds and breasts

- Positive / negative emotions for wounds

- Positive / negative emotions for the shape of the breast - Emotion that shakes with deformation of wound

- Feeling of breast loss

\section{Image of the body before and} after surgery

- Image before surgery (for wound and breast)

- Image gap before and after surgery
Expectation and conflict with a beautiful breast

- Expectations for a beautiful breast Eliminate expectations for beautiful breasts - Positive / negative thoughts on reconstruction 

Treatment status Treatment does not go well - Anxiety about whether treatment goes well
How to grasp my body

- Japanese body view

- Evaluation concern

- Beliefs and values about the body

- Important Other's Values

- Japanese hot spring culture

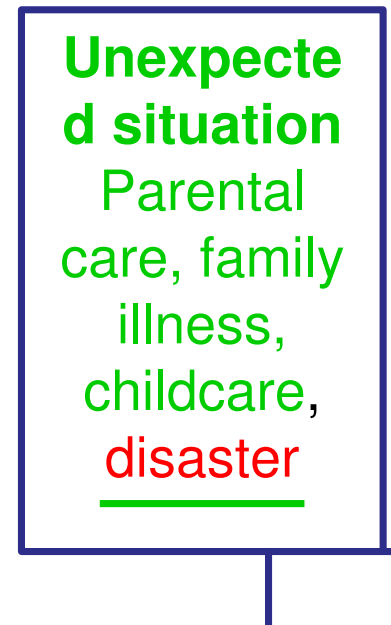

Invention that does not expose wound in public place

- Bathing method of public bath

- Changing clothes for public baths
Be prepared to undergo a mastectomy

- Active self-

determination

- Regret the way of surgery

\section{Puzzle of self-}

perception

- Life style not different from before

- A lifestyle that is

forced to change

- Compensation problem 